\title{
When Do You Want It? Time, Decisions, and Public Policy
}

\author{
John G. Lynch Jr. and Gal Zauberman
}

\begin{abstract}
Most consumer decisions involve trade-offs of costs and benefits over time. The research literature on "intertemporal choice" examines behavioral regularities in how people think about such decisions, drawing from marketing, psychology, and behavioral economics. This diverse literature is relevant to the analysis of public policy issues related to consumers' discounting of future outcomes "too much" compared with sooner outcomes. A stream of outcomes can be viewed as occurring in three temporal regions: the present, the near future, and the more distant future. Somewhat different research streams have developed around the topic of underweighting outcomes in the distant (compared with the near) future and of overweighting outcomes in the present compared with any point in the future. The authors review key concepts from the literature on underweighting the distant future versus the near-term future to analyze policy issues related to consumers' saving for retirement and their response to rebates. The authors review key concepts from the literature on impulsive behavior and present-biased preferences to analyze the problems of self-control that people have in their consumption of "sin" products that are proximate and that affect rewards in the present. The authors critique current information and incentive remedies that ignore behavioral principles from the literature, focusing their recommendations on policy interventions designed to influence eating habits and obesity and on cooling-off laws that govern return policies for consumers' big-ticket purchases.
\end{abstract}

M ost consumer decisions involve trade-offs of costs and benefits over time. For example, a consumer suffering from chronic pain may weigh the nearterm advantages of a Cox-2 inhibitor drug, such as Vioxx, in protecting the stomach against a slight elevation in heart attack risk in the more distant future. A dieter may weigh the immediate pleasure of a luscious chocolate cake against short-term weight gain or long-term problems of obesity. A person buying a refrigerator may weigh purchase price against life-cycle energy cost. A factory worker may weigh whether to replace a two-year-old car with a shiny new model against driving the old car and saving for retirement.

John G. Lynch Jr. is Roy J. Bostock Professor of Marketing, Fuqua School of Business, Duke University (e-mail: john.lynch@duke.edu). Gal Zauberman is Assistant Professor of Marketing, Kenan-Flagler School of Business, University of North Carolina, Chapel Hill (e-mail: zauberman@unc.edu). After July 1, he will be at the Wharton School, University of Pennsylvania (e-mail: zauberman@wharton.upenn.edu). The authors are listed in alphabetical order, and they contributed equally to the article. The authors thank participants at the Duke University Conference on Helping Consumers Help Themselves: Improving the Quality of Judgments and Choice for their comments, especially Eldar Shafir. They are particularly grateful to Joseph Mulholland and Janis Pappalardo of the Federal Trade Commission and to JPP\&M editor Joel Cohen for comments on the analysis of deceptiveness or unfairness of rebates. This article was processed and accepted by editor Joel Cohen.
A home computer buyer must decide whether to upgrade to a new package that received better reviews but would involve significant time investment in the short run to learn the new package.

In making such decisions, consumers typically weigh immediate outcomes more heavily than more distant ones. Although there are normative, "rational" reasons to do so, there are many domains that are relevant to public policy in which consumers make "mistakes" by giving undue weight to outcomes in the present or the near term compared with those in the long term. Therefore, understanding how consumers think about present and future consequences is critical to any public policy analysis of consumer decisions that have an intertemporal component. Research in marketing, psychology, and behavioral decision making can inform such public policy analysis.

Economic theory suggests that the normative model for intertemporal decisions is the discounted utility model (Samuelson 1937). Utility at time $t$ for a stream of outcomes from time $\mathrm{t}$ to some end time $\mathrm{T}, \mathrm{Ut}\left(\mathrm{c}_{\mathrm{t}}, \ldots, \mathrm{c}_{\mathrm{T}}\right)$, is simply the weighted sum of instantaneous utility, $u\left(c_{t}+k\right)$, at each period $\mathrm{t}+\mathrm{k}$ over that range:

(1) $\mathrm{U}^{\mathrm{t}}\left(\mathrm{c}_{\mathrm{t}}, \ldots, \mathrm{c}_{\mathrm{T}}\right)=\sum_{\mathrm{k}=0}^{\mathrm{T}-\mathrm{t}} \mathrm{D}(\mathrm{k}) \mathrm{u}\left(\mathrm{c}_{\mathrm{t}+\mathrm{k}}\right)$, where $\mathrm{D}(\mathrm{k})=\left(\frac{1}{1+\rho}\right)^{\mathrm{k}}$.

Here, $D(k)$, the weight attached to utility in time $t+k$, will be 1 when $k=0$ (delay $=0$ ). If the discount factor $\rho$ is positive, utility in subsequent periods will receive progressively less weight. 
Despite its normative appeal, this model is descriptively inadequate. Two excellent recent reviews summarize a large body of work in psychology, behavioral economics, and consumer research that has documented numerous "anomalies" in how consumers actually make decisions between smaller, sooner rewards or costs and larger, later ones (Frederick, Loewenstein, and O'Donoghue 2002; Read 2004). Different studies show vastly different revealed discount rates that seem to depend on a host of contextual factors that are normatively irrelevant. We do not review this vast literature in any detail; rather, we focus our analysis on classes of consumer decisions in which consumers make potentially bad decisions by being myopic and underweighting future consequences.

Intertemporal decisions can involve a stream of outcomes that occur in the present, the near future, and the more distant future. Somewhat different research literature has developed around the topic of underweighting outcomes in the distant (compared with the near-term) future and of overweighting outcomes in the present (compared with any future period).

This literature also maps onto different public policy domains. Underweighting the distant future versus the nearterm future is relevant to policy that affects behaviors in which the payoffs for good behavior occur in the long term, such as saving for retirement or environmental protection. ${ }^{1}$ Another set of problems arises when the decision involves outcomes that are more proximate. A large body of work shows that when decisions involve immediate rewards, people are impulsive and exhibit present-biased preferences that cannot be accounted for simply by assuming a high discount rate. This can lead to problems of self-control to avoid short-term temptations ("sin" products). Work in this area is relevant to policy interventions designed to affect eating habits and obesity and influence teens' risky sexual behavior and to cooling-off laws that govern return policies for consumers' big-ticket purchases.

\section{Weighting the Near-Term Versus Long- Term Future}

We begin our analysis with an examination of decisions that involve trade-offs, rewards, or costs in the near-term future versus the more distant future. In some important policy domains, the question arises whether consumers discount "too much"; that is, are they insufficiently attentive to outcomes that will occur in the more distant future? For example, it has often been noted that U.S. workers save relatively little for retirement (Thaler and Benartzi 2004; Thaler and Sheffrein 1981). This implies that people discount too much; that is, they too strongly prefer consumption in the near future compared with consumption in later periods.

Related to the issue of private savings is the issue of government entitlements for retirees. Debates about how to save the social security system are sometimes framed in terms of

\footnotetext{
1Other articles in this special issue address the issue of the psychology of saving versus spending (see Bertrand, Mullainathan, and Shafir 2006; Botti and Iyengar 2006; Briley and Aaker 2006).
}

intragenerational fairness to rich versus poor citizens, but these debates are equally relevant to intergenerational tradeoffs, namely, below-the-surface disputes about the relative weight that should be placed on public burden experienced in the present versus a more distant point in the future, when new tax revenues would need to be raised to cover social security payments. Similarly, policy analysis of environmental protection often pits the current generation's consumption of resources and disposal of wastes against the interests of subsequent generations (Okrent 1999; WadeBenzoni 1999).

In each case, it could be argued that consumers, or their governmental representatives, are making a mistake. If incurring a deficit to reform social security is bad for the economy today, why should that matter more than the burden of an even larger deficit in 20 years? Work on intertemporal choice can shed light on the thinking that underlies consumer perceptions of these issues.

\section{Psychological Foundations of Discount Rates}

Discounting has multiple causes. Frederick, Loewenstein, and O'Donoghue (2002) and Read (2004) distinguish "time preference" from "discounting." They define time preference as a preference to receive utility today versus the same utility in the future. They use the broader label of "discounting" to refer to any reason a person might prefer consumption today to consumption tomorrow, including the expectation that the future consequence confers less utility than a similar, present consequence. Frederick, Loewenstein, and O'Donoghue note that a future benefit might have less expected utility than a more immediate benefit because the future consequence is less certain to occur or because a person anticipates that his or her tastes may change in the future. A future cost may seem less of a burden than a present one because opportunity costs are greater in the present or because a person expects to have more wealth in the future.

All these examples are arguably "rational" reasons to discount future outcomes. For example, if a person is unsure of whether he or she will be alive in 20 years, it may be rational to value current consumption over later consumption. If a person believes that, in the future, his or her tastes might change, it may be rational to give less weight to future consumption of a good that is highly valued today. If a person believes that investing a resource now will force him or her to forgo other valued opportunities that need not be forgone if invested in the future, it may be rational to view investment in the future as less of a burden than investment today. If a person expects to be wealthier in the future, it may be rational to prefer to pay a much larger amount in several years than a small amount now.

As we subsequently show, however, discounting behavior is caused by certain psychological factors that cannot be anticipated by an economic analysis. We review two general theories of discounting, one that explains discounting of future resources according to their greater availability in the future than today and one that points to systematic differences in the cognitive representation of events in the near future versus the more distant future. We analyze consumer decisions about saving and spending and about consumer 
response to rebates in terms of these two theoretical frameworks.

\section{Resource Slack and Resource Differences in Discount Rates}

Zauberman and Lynch (2005) note that Equation 1 implies that utility is being discounted, so any resource that affects utility might be expected to be discounted at the same rate. However, they note that evidence exists that contradicts this assumption. For example, Chapman (1996) estimates people's discount rates for health and money and finds little correlation between individual money and health discount rates.

Zauberman and Lynch (2005) propose a general theory of why resources might be discounted at different rates, founded on the concept of perceived "resource slack" at different points in time. Slack is the perceived surplus of a given resource available to complete some focal task. Zauberman and Lynch argue that people discount delayed expenditures of a limited resource when (1) immediate investment of the resource would block the accomplishment of other concurrently activated goals that require the resource and (2) they expect to have more resource slack in the future and, thus, less sacrifice of other highly valued goals that require the same resource. Discounting and desire to delay investment are driven by perceptions of "slack gain" (or loss) for a given resource over time.

Zauberman and Lynch (2005) evaluate this slack gain theory by testing deductions about how two generic resources, time and money, are discounted at different rates. They predict and find that, on average, people expect to have more time slack in the future than they do today but that people do not have an equally optimistic expectation of having more money in the near future. In a series of experiments, Zauberman and Lynch show that people exhibit higher discount rates for investments of time than for investments of money. That is, people would be willing to invest considerably more time for some worthwhile pursuit in a month than tomorrow, but the same is not true with money. ${ }^{2}$

Zauberman and Lynch (2005) further show that the greater discounting of time than of money occurs only under conditions in which people expect slack to increase in the future more rapidly for time than for money. Participants who expected to have more money but not more time in the future showed the opposite pattern; that is, they discounted future money donations more than future time donations. This was important in demonstrating the key causal role of changes in slack in explaining discounting and differences in how people discount different resources.

The everyday manifestation of this irrational exuberance about time that most people exhibit is what Zauberman and Lynch (2005) call the "Yes ... Damn!" effect. People over-

2This might explain how guest editors John Lynch and Wendy Wood convinced all the other authors to write invited articles for this special issue. Despite those authors' acute sense of being overcommitted in the present, they imagined being less busy in the future when the time came to write the articles. commit and agree to time-consuming activities in the future ("Yes") that they would refuse if such activities needed to be done right away because they expect to have less competition for their time in the future than in the present. When the distant future turns into today, however, people discover that other competing activities have arisen and that they are just as busy as they were a month ago when they committed; thus, they curse themselves- "Damn!"

The interesting question is, Why do people not learn from their repeated mistakes? Zauberman and Lynch (2005) show that people are much worse at predicting supplies of spare time than they are of spare money. Moreover, perceptions of time slack are "hyperbolic"; that is, at a distance, two days in the future seem similar in spare time, but as the first of those days draws nearer in time, people begin to view that day as likely to be much busier than the later day. Similar patterns are not found for money. So, people are particularly bad at anticipating when in the future they might actually have time to add some time-consuming activity without regretting it.

\section{Construal-Level Theory}

A compelling body of work on construal-level theory illuminates differences in how people represent events in the near and more distant future (for reviews, see Liberman, Trope, and Stephan, in press; Trope and Liberman 2003). ${ }^{3}$ According to construal-level theory, people represent events at a "high level" in the distant future and at a "low level" in the more immediate future. In the near future, people think concretely about the feasibility of action, that is, what constraints on action exist. In the more distant future, thoughts are dominated by more abstraction about the desirability of the same events.

In one of numerous demonstrations, Liberman and Trope (1998) asked Israeli students to choose between assignment topics, some of which had to be completed in English and some in the students' native Hebrew. Some assignments were to be completed within a week, and some were to be completed much later in the term. For each point in time, students chose between assignments in English, which were shown in pretests to be more interesting (high desirability but low feasibility), and assignments in Hebrew on less interesting topics (low desirability but high feasibility). The results showed that in the near term, people chose the less interesting assignments in Hebrew. For the more distant future, they chose the more interesting assignments in English. Thus, the relative weights of feasibility and desirability considerations change as a function of temporal distance.

\footnotetext{
${ }^{3}$ Liberman and Trope (1998) show that people think about distant events in terms of more superordinate goals (ends) and nearer events in terms of more subordinate goals (means to ends). The greater abstractness of thoughts about the more distant future is reflected in people using fewer, broader categories to classify events in the long term than in the short term (Liberman, Sagristano, and Trope 2002, Study 1). Distant events are represented in a less complex, less multidimensional way (Liberman, Sagristano, and Trope 2002, Study 2). More distant events are decontextualized, and nearer events are more contextualized (Nussbaum, Trope, and Liberman 2003).
} 
Other findings show that for distant events, people give relatively more weight to primary, core (i.e., high level) attributes of products and goals for their use and less weight to secondary, surface (i.e., low level) aspects of the same products (Trope and Liberman 2000). For example, in a choice between two clock radio sets, one with good sound but a less useful clock and one with a good clock but lowerquality sound, sound quality may be higher level if the main reason for purchasing the radio is to listen to music, but if the primary purpose in buying a clock radio is to wake up in the morning, the clock may be primary. Trope and Liberman (2000) show that in each situation, the relative weight of the primary feature increases with temporal distance.

Sagristano, Trope, and Liberman (2002) further argue that for probabilistic events, payoffs are high level and probabilities are low level. After all, the payoff is the primary reason for taking the gamble, and probability is just a constraint on achieving the payoff. Sagristano, Trope, and Liberman show that in evaluations of gambles and choice among gambles, people who make decisions that are to take effect in the near term give relatively more weight to probability and less to payoff than if the outcomes of the same gambles were to occur only in the more distant future.

Finally, Eyal and colleagues (2004) argue that in people's evaluations of actions, pros (i.e., reasons to undertake an action) are higher level and more central than cons (i.e., constraints on action). Eyal and colleagues demonstrate that people give more weight to pros and less weight to cons when events are more distant than more immediate.

In summary, numerous studies have shown that mental representations change with the temporal distance of the outcome or event. These changes in representations change the features of outcomes that are weighted more heavily in decisions. Building on temporal construal theory, Zhao, Hoeffler, and Zauberman (2005) show that asking people to simulate the benefits of an immediate outcome mentally before making a decision causes their immediate decisions to become more consistent with distant-future preferences. Policy makers who understand these principles can encourage behaviors that people view as more attractive in the long run than the short run by interventions that change people's temporal perspective and, thus, the weighting of feasibility and desirability considerations.

\section{Application to Saving for Retirement}

People fail to save for retirement because in the short run, saving exacts a cost. Thaler and Benartzi (2004) have trademarked a plan called Save More Tomorrow, which asks people to precommit to save future money from raises for retirement. They report dramatic success in getting employees to join and in increasing the annual savings rate for retirement from $3.5 \%$ to $13.6 \%$ over the course of 40 months.

Thaler and Benartzi (2004) do not interpret their plan in terms of construal-level theory. They argue that people are unwilling to save in the present, though they are willing to precommit to saving in the future because of loss aversion and a mechanism similar to an endowment effect (Kahneman, Knetsch, and Thaler 1990). ${ }^{4}$ However, alternative

4In the endowment effect, participants are randomly assigned to be buyers or sellers of a good (e.g., a mug). Sellers endowed with the mug become explanations can be offered from the perspective of temporal construal theory. It is clear that when people are making decisions about saving in the current period, constraints and costs should loom large compared with the potential benefits of having adequate savings for retirement. When a person is given a choice of precommitting future raise money to retirement savings, the consequences are more temporally distant. Consequently, people give more weight to benefits and less to costs, causing participation to increase.

The same issue can be analyzed from the perspective of Zauberman and Lynch's (2005) resource slack theory of discounting. It is common for people to observe that their expenses always just outstrip their financial resources. So, if people feel too cash constrained in the present, they will probably feel just as cash constrained in the future. However, because people imagine that they will have more financial resource slack after getting a raise, they are willing to precommit to save tomorrow what they would not save today. Critically, if a person waited until the time of receiving the raise to suggest banking it for retirement, many people would decline because they would not believe that they had adequate money slack to spare more money for savings.

Thaler and Benartzi (2004) find that though people who precommit to save can opt out, they rarely do so. They argue that people do not opt out because of "status quo bias" (Samuelson and Zeckhauser 1988). However, status quo bias is more of a label for a general empirical phenomenon than an explanation. Many processes are compatible with preference for the status quo. For example, people may stay with the status quo because they fail to think about it later.

Slack theory provides an alternative explanation of why people do not opt out when the raise arrives: Opting out takes a small amount of time and effort that seems like a very small switching cost when a person precommits several months before receiving a raise, but switching costs that seem very small in the distance prove to be much more binding when the time arrives to incur them (Zauberman 2003). This inability to forecast the subjective magnitude of a future time cost is related to Zauberman and Lynch's (2005) Yes ... Damn! effect; that is, people are unable to anticipate the opportunity cost of their time in the future. Consequently, when their raises arrive, people may wish to opt out, but they have a preference to delay or procrastinate in finding the time to do so. Suppose that a company has a Save More Tomorrow savings plan for precommitting to save raise money but with an opt-out alternative that could be effortlessly chosen when the raise arrives, with paperwork to be filled out the following month. Slack theory predicts that opting out would be much more common in this circumstance than if the choice to opt out required immediate time costs of filling out paperwork (for evidence consistent with this conjecture, see Madrian and Shea 2001).

\section{Deceptive or Unfair Rebates?}

Construal-level theory predicts that benefits loom larger than costs in the future but not in the present (Eyal et al. 2004). This implies that rebates that require effort to redeem should become a more potent inducement to buy if con-

attached and set reservation selling prices substantially higher than the buyers' reservation prices. 
sumers are barred from redeeming the rebate for several weeks (Soman 1998). The same point follows from resource slack theory (Zauberman and Lynch 2005) if time required to redeem rebates is discounted at a faster rate than the money reward that comes from redeeming rebates.

Soman's (1998) experimental participants made a hypothetical choice between two pairs of snow pants, one promoted with a rebate and one with no rebate. The rebates required effort to redeem in the form of driving to another location. He varied the face value of the rebate, the distance to be driven to redeem the rebate, and whether the rebate could be redeemed immediately or only at some point in the future. The results showed that the percentage of respondents who chose the promoted alternative actually increased when the rebate could not be redeemed until later. Why did this occur? Soman found that the effect of the monetary size of the rebate was unaffected by whether rebate redemption was immediate or in the future. That is, people did not discount the future benefit. However, they did discount the future cost. In the immediate condition, people were highly sensitive to the level of effort to redeem the rebate; in delayed conditions, they were insensitive to effort. That is, future effort was discounted steeply.

In another study, Soman (1998) recruited respondents to fill out a short survey for $\$ 1$ and then gave them the chance to forgo that amount for a larger amount if they would complete a second survey. He varied independently the amount of effort to complete the survey (four pages or eight pages), the payment if it was completed ( $\$ 2$ or $\$ 4$ ), and the exact time at which people were instructed to redeem the questionnaire (in two weeks, in four weeks, or at any point in time over the next four weeks). The results showed that the payment amount had a large effect on the decision whether to undertake a second survey, but it had no effect on whether the payment for the longer survey was actually redeemed. In contrast, the effort to be undertaken had relatively little effect on choice because it would not be experienced until the future, but amount of effort had a large effect on redemption.

In light of these findings on temporal construal, resource slack, and Soman's (1998) work on the "illusion of delayed incentives," policy makers might devote some consideration to whether rebates are a "deceptive" or an "unfair" form of inducement to buy. At first blush, the obvious answer would seem to be no. Rebates seem to be a legitimate promotional tool as long as sellers adequately communicate the responsibilities of consumers to qualify for and redeem a rebate. Indeed, rebates are popular with consumers for offering savings.

However, what if consumers are led to purchase one product over the competition, relying on an unrealistic expectation (based on aggregate evidence) that they will later redeem the rebate? As we discussed previously, such consumer expectations are typically overly optimistic. We are not aware of seller disclosures of the percentage of customers buying on rebate who subsequently redeem. Failure to provide consumers with accurate information about redemption likelihood, when consumers typically believe otherwise, might be construed as a deceptive marketing practice. Federal Trade Commission (FTC) policy on deception (Ford and Calfee 1986; Miller 1983) holds that acts or practices are deceptive if (1) there is a representation, omission, or practice that is likely to mislead the consumer; (2) the "reasonable" consumer would be so deceived; and (3) the representation, omission, or practice is material.

Sellers appear to understand better than consumers that when the time comes to redeem the rebates, many people do not follow through. Silk and Janiszewski (2005) note that apart from coupons, rebates are the most popular form of promotion by consumer goods companies; they are also the most common form of promotion used by technology retailers, in part because rebates drive demand while limiting the number of consumers who purchase at a discount. Silk and Janiszewski surveyed 35 promotion managers who regularly used rebates as a form of inducement to buy; the managers estimated an overall redemption rate of $51 \%$, with significant variation across big-ticket items versus inexpensive consumer goods. In line with our arguments, they estimated that $64 \%$ of nonredemption is by consumers who would have made a different choice without the rebate; they estimated that only $36 \%$ of nonredemptions are by consumers who would have bought the same alternative in the absence of a rebate.

A parallel might be drawn between consumers' misunderstanding of the likelihood that they will enjoy the proffered benefit of a rebate-reduced price and the likelihood that they will benefit from a weight-loss supplement. Consider an advertisement that trumpets "Lose 5 pounds in 10 days," with ad copy about how easy it is to lose weight by taking the product three times a day, accompanied by before-and-after pictures (FTC, Bureau of Consumer Protection 2001). If the product works, but only in conjunction with a rigorous diet and exercise program, the advertisement might be deceptive if it does not make sufficiently salient the additional conditions that make even motivated consumers unlikely to lose the promised weight. The FTC has also advocated disclosures of success rates (Cleland et al. 2002).

With rebates, a similar argument could be made that sellers should disclose and make salient the steps that are required to redeem as well as the success rate (i.e., the frequency of rebate redemptions). If consumers understand that they are unlikely to redeem a rebate, they might give the rebate less weight in choosing among competing products than a somewhat smaller, though immediate, price reduction. Such an informational remedy might provide incentives to marketers to compete by offering rebates that were more attractive and easier to redeem (cf. Gabaix and Laibson 2006; Mulholland 2005).

The FTC is also authorized to act if it considers a marketing practice unfair. Some people may believe that knowingly offering a rebate that a substantial percentage of consumers are unlikely to redeem (though they believe otherwise) is an unfair competitive practice. However, the FTC appears to operate under a definition of unfairness that makes this outcome unlikely: "As codified in 1994, for a practice to be unfair, the injury it causes must be (1) substantial (2) without offsetting benefits and (3) one that consumers cannot reasonably avoid" (Beales 2003, p. 195).

Consumers who follow the redemption protocol receive the benefit, and they might point out that those who do not 
could have easily avoided the financial loss. 5 However, it is highly predictable that in the aggregate, consumers will have low redemption rates. In Silk's (2005) incentivecompatible studies of rebate redemption, people were reasonably accurate in their predictions of the aggregate level of redemption, but they expected that they were personally much more likely than the average person to redeem. Notably, among participants who chose an alternative with a rebate, there was no correlation between their estimated probability that they would follow through to redeem and their actual redemption behavior.

Even if there is deception or unfairness, no regulatory intervention might be warranted if consumers learn over time from feedback that they do not follow through to redeem rebates (for evidence about consumer learning of repeated choices involving the same rebate choices under certain restrictive conditions, see Silk 2004, 2005), but we argue that many purchases consumers make because of rebates are "new." If consumers buy a software package with a rebate, for example, they might not remember or reflect on whether they failed to follow through with redemption in some other product class on some longdistant prior occasion.

Public policy favors less restrictive informational remedies if rebates are judged deceptive or unfair. However, we are not sanguine that these kinds of standard informational remedies would produce dramatic effects on consumers' susceptibility to rebates or alter their probability of redemption. People fail to redeem rebates because of fundamental and predictable principles of human motivation and cognition. Failure to redeem rebates is just a special case of Zauberman and Lynch's (2005) Yes ... Damn! effect. People systematically underestimate the burden of time costs to be borne in the future and fail to learn from personally relevant base-rate information that they later regret committing to time-consuming activities in the future. As work in temporal construal theory has shown, it is a fundamental property of human cognition that people can comprehend "complete" information about costs and benefits of an action at a temporal distance and not appreciate how they will reevaluate it when the action draws near.

If informational remedies are likely to have weak effects, what else might work? One approach would be to restrict sellers' ability to offer rebates with a long time frame, on the grounds that such rebates are inherently deceptive or unfair (as supported by empirical work and sound psychology). If

\footnotetext{
${ }^{5}$ Surprisingly, the balance of costs to benefits may be more favorable for rebates with short deadlines to redeem (cf. Tversky and Shafir 1992). Silk (2005) finds that with longer deadlines for rebate redemption, people are more likely to choose a rebate option over alternatives with no rebate but less likely to redeem the rebate. In Silk's study, people paid their own money for movie tickets and had a choice between a moderate price with no rebate and a lower price with a rebate that would make that alternative cheaper if redeemed. Consistent with our resource slack analysis, a 21-day deadline rather than a 1-day deadline for rebate redemption on movie tickets caused consumers to consider fewer factors that could potentially interfere with redemption. However, consumers with the longer deadline subsequently reported that they had encountered more distractions that interfered with redemption than consumers who had a 1-day deadline.
}

rebates require fairly immediate action, people could realistically appraise their likelihood of following through. Placing a short redemption deadline on consumers is no hardship, because as we noted previously, people are more rather than less likely to redeem a rebate with a shorter deadline. The only reason this might pose a hardship to marketers is if there were a higher proportion of redemptions, but of course, this was the bargain they presumably made with their customers.

An alternative remedy would be to require retailers to file manufacturer rebates at checkout rather than leaving it to consumers to mail in rebates from home. This would prevent buyers from falling prey to their own self-deceptions about their greater availability of time in the future. Silk (2005) notes that a bill in California (SB 1154 Figueroa) proposed to reduce the type of paperwork consumers are required to submit to qualify for a rebate. Governor Schwarzenegger vetoed the bill in September 2004.

It is outside the scope of our expertise to judge whether any remedy is likely to be considered or adopted for promotional incentives (e.g., rebates) that provide an economic benefit to some consumers but significant costs to others. Our aim is not to propose solutions but to suggest that a better understanding of consumers' psychological limitations and mental representations of temporally near and distant outcomes and actions would facilitate such an assessment. This type of analysis (and contributions from psychological science) could also provide insights that might be useful in identifying circumstances that contribute to deceptive and unfair practices.

\section{Other Sales Practices Preying on Consumers' Illusions About Time}

We noted previously that people chronically believe that they will have more time in the future than they have in the present (Zauberman and Lynch 2005). Many high-ticket products require a significant investment of time to enjoy the benefit (e.g., time-share vacation homes, season tickets to sporting events or concert series, gym memberships, DVD subscription services). The market for many of these goods may depend in part on consumers' false presuppositions that they will be able to engage in future activities that they are not able to engage in today.

A possible remedy might be to regulate products and services with these characteristics to allow consumers lenient return conditions after some modest period of time in which their long-term low-usage level will have a chance to be revealed to new customers. Ironically, however, the behavioral literature suggests that such lenient return policies have the opposite effect of the intended purpose. Wood (2001) shows that lenient return policies encourage people to buy under the false presumption that they are "trying" rather than committing to a product or service; subsequently, they are as unwilling to reverse a decision as if the return policies had been strict. Consistent with our resource slack account, consumers believe that when the product is purchased or the membership is activated, they will follow up to opt out, but when the time comes, they do not believe that they have sufficient time slack to do so. In this case, class action lawsuits may provide a better remedy than regulation. 


\section{Time-Inconsistent Preferences: Extreme Weight on the Present}

In the preceding section, we focused on the psychological processes that lead to the devaluation of consequences in the more distant future. In this section, we focus on special problems that arise when the current period is disproportionately higher weighted than all other periods, including the near future. That is, the weight of outcomes declines especially steeply from to to $t 1$ compared with any other $t(n)$ and $t(n+1)$, and this cannot be explained by choosing some appropriate value of the discount rate $\rho$ in Equation 1.

Equation 1 implies that if people prefer a smaller reward at time $\mathrm{t}(0)$ to a larger reward at $\mathrm{t}(1)$, they should prefer the same smaller reward at $t(n)$ to the larger reward at $t(n+1)$. This follows mathematically from Equation 1 because the ratio of the weight of $t(n) / t(n+1)$ should be the same for all values of $n$. Instead, hundreds of studies have found that preferences are present biased (Strotz 1956; Thaler 1981) and, thus, time inconsistent. For example, if people are asked whether they prefer two cookies today or three cookies tomorrow, many people might choose two cookies today, but if the same people are offered the choice of two cookies in a month or three cookies in a month plus one day, most would choose the larger, later reward over the smaller, sooner one. This phenomenon occurs especially when outcomes are represented concretely (Malkoc and Zauberman 2006) and are tangible, immediate, and physically present (Metcalfe and Mischel 1999).

This phenomenon of disproportionately weighting outcomes in the current period and the consequent reversal of preferences as distant consequences draw near in time has been demonstrated repeatedly in both humans and lower animals (e.g., Ainslie and Herrnstein 1981). In the literature, this has been referred to as "decreasing impatience," "present-biased preferences," and "hyperbolic discounting," and it has been modeled with hyperbolic (e.g., Ainslie 1975; Ainslie and Haslam 1992; Kirby 1997) and quasi-hyperbolic discounting functions (e.g., Laibson 1997; O'Donoghue and Rabin 1999; Zauberman 2003) rather than the kind of exponential discounting function in Equation 1. What is common to these alternative models is the assumption that more weight is given to outcomes in the first period than in subsequent periods and that this tendency becomes stronger as the first period draws nearer in time. Therefore, the ratio of the weight of outcomes at $t(n) / t(n+1)$ increases as $t(n)$ draws nearer in time.

\section{Self-Control Problems and Precommitment}

Time-inconsistent preferences lead to problems of selfcontrol. The problem is that the same decision between smaller, sooner and larger, later rewards appears different when the smaller, sooner reward is close from when it is viewed as far off in time in either the future or the past. Before going out for dinner, it is clear to a dieter that he or she should avoid a rich dessert that will add pounds in the long run, but when the moment of truth arrives along with the dessert cart, the dieter may find that the fattening chocolate cake is irresistible, even though it interferes with the attainment of a larger, long-term goal of health. Similarly, a recovering alcoholic may resolve to drink water at a party but find him- or herself powerfully attracted to drink alcohol when it is readily available.

If people consider it in their long-term interests to be guided by the preferences from a greater distance, how do they avoid giving in to the temptation to choose the smaller, sooner reward when it draws near in time? In Homer's Odyssey, the irresistible Sirens attracted sailors by their sweet singing, luring them to shipwreck and death. Wanting to hear their song and yet survive, Ulysses plugged the ears of his oarsmen with wax and ordered them to lash him to the mast so that they would not give in to the temptation and turn his ship toward the Sirens.

Research has shown that as with Ulysses, both humans and animals sometimes select precommitment devices that constrain their choices or that self-impose penalties for deviation from their long-term preferences. Some rats can learn to press a bar that allows them to avoid making a choice between an immediate, smaller reward of food pellets and a larger, later reward (Ainslie 1975). Similarly, humans have been shown to use precommitment devices, such as buying small packs of sin products (e.g., cigarettes), to constrain consumption (Wertenbroch 1998). Ariely and Wertenbroch (2002) show that students who were wary of their own temptation to procrastinate chose early assignment deadlines for themselves and imposed costly penalties for failing to meet the deadlines. Students who did not make such choices received lower course grades, implying that the use of these costly bets is functional.

From a public policy perspective, a key point is that internal self-control and externally induced self-control are substitutable (cf. Mazar and Ariely 2006). Fishbach and Trope (2005) show that if there are external inducements to influence the choice of larger, later rewards over smaller, sooner ones, people reduce their use of internal self-control strategies. For example, if a company health plan rewards people for engaging in more physical exercise, this undercuts personal self-control motivation. Especially dangerous is a policy that imposes external inducements for temporary selfcontrol. When the external inducement is removed, internal motivation is likely to be weaker than if the external inducement had never been introduced. In addition, we subsequently argue that in many, if not most, situations, people regularly fail to exercise self-control and avoid temptation because they fail to predict the full power of the situation.

\section{Affective Determinants of Present-Biased Preferences and Impulsiveness}

As we described previously, there is an extensive body of evidence that people weigh the present more than any other time period. This is especially true for outcomes that are vivid, tangible, and immediate. Metcalfe and Mischel's (1999) work on "hot/cool" systems illustrates this principle. The desire for immediate gratification-for a cookie, for example-is significantly stronger when this cookie is visible than when it is out of sight.

Present-biased preferences are governed by different psychological causes from standard discounting of distantfuture outcomes. As far back as Freud ([1923] 1962, 1933), the strong power of proximate stimuli has been attributed to 
the animal instincts of the id, and the more reflective preferences have been attributed to the ego, which keeps the id under control. Freud likened the id to a horse and the ego to the rider that keeps the horse under control and that engages in more deliberative long-term planning. Most recent theorizing has attributed present-biased preferences to the operation of relatively automatic, hot affective systems that can sometimes be overridden only by some cool, effortful, deliberative system.

\section{Hot Present-Biased Preferences}

Loewenstein's (1996) influential concept of "visceral factors" holds that some rewards may be discounted steeply because they become overpoweringly attractive as they draw nearer (in temporal or physical distance) when in a state of deprivation, causing drivelike affective reactions. People exhibit a willingness to trade any amount of another resource for the visceral reward. For example, hunger, thirst, sexual arousal, addictive drug deprivation, and sleep deprivation have the potential to overwhelm other motives that the decision maker might deem to be more important when viewed from a distance before or after a decision.

Loewenstein (1996) gives the example of sleep deprivation interrogation techniques used by the Israeli Mossad. Detainees are later baffled at how they were induced to reveal so much information without any physical threat, but in a deprivation state, the appeal of an hour of sleep is so great that the detainee will betray a cause that he or she viewed as the most central value in life. Similarly, people who, in a cool state, never imagined engaging in risky, unprotected sex change their preferences when in a state of sexual arousal (Ariely and Loewenstein 2006).

Loewenstein (1996) contrasts visceral factors with other, more utilitarian resources that exhibit lower, more "normal" levels of impatience and less pronounced interaction of stimulus proximity and deprivation state. Shiv and Fedorikhin (1999) examine choice between hedonic vices, such as chocolate cake, and virtues, such as fruit salad, and show that people are more likely to choose the virtuous product when they have more mental resources and when stimulus proximity is less-for example, when the physical dessert is replaced by a picture. This is consistent with Metcalfe and Mischel's (1999) work on hot/cool systems, which also points out that psychological proximity enhances bias toward the present. Work showing higher discount rates for addictive substances than for money is also relevant (Baker, Johnson, and Bickel 2003; Kirby, Petry, and Bickel 1999). This again points to the idea that high-arousal states lead people to focus on the present and virtually ignore future consequences.

Recent research in neuroscience provides further evidence that different mechanisms operate when decisions involve outcomes in the immediate present. Different regions of the brain are activated during lower-level automatic responses and higher-level reasoning. The two types of activation have been shown to have different neural correlates in studies that use fMRI (functional magnetic resonance imaging), a technique that measures blood flows to different regions of the brain, as a function of different types of stimulation. McClure and colleague (2004) find that the limbic system is more activated in decisions that involve immediate rewards, whereas the areas of the lateral prefrontal cortex are activated independent of the timing of the reward. This suggests that information disseminated by regulators to influence impulsive behavior is unlikely to be effective at the time of decision when a consumer is in a hot arousal state, because these decisions are likely to be dominated by the lower-level, automatic responses of the limbic system.

\section{Misprediction and the "Hot/Cold Empathy Gap"}

A policy analyst may question why consumers need protection from themselves when they make "impulsive" choices that disagree with their long-term preferences. After all, if consumers know that their preferences will change in the face of temptation in a way that violates their long-term preferences, is it not their responsibility to avoid the temptation? For example, dieters might avoid the temptation of junk food simply by avoiding entering a fast-food establishment. Teenagers who do not want to be sexually active can avoid putting themselves in a situation in which they will be tempted or able to act on the temptation. ${ }^{6}$

We noted previously that in some cases, people are able to make use of precommitment devices. A fundamental reason people so often fail to take such self-control measures is what Loewenstein (1996) and others label the "hot/cold empathy gap." Research shows that the power of the present and immediate gratification can be overwhelming in a way that people do not anticipate (e.g., Brendl, Markman, and Messner 2003). People in a cold state mispredict how they will behave in a hot state. If people cannot imagine how overpowering the temptation will be, they cannot be expected to take protective action to avoid the tempting situations.

Loewenstein (1996) argues that this misprediction arises from a mismatch in affective intensity levels in a hot state and in a cold state. When people are in a given state of arousal (i.e., hot), they cannot anticipate how they will behave when they are in a different state (i.e., cold). For example, people purchase more groceries when they are hungry. There is also evidence that people in cold states cannot anticipate their behavior in a hot state. For example, Read and Van Leeuwen (1998) asked participants to choose in advance between healthful and unhealthful snacks (i.e., fruit versus junk food) that they would receive one week later. Participants made this decision when they were either hungry (late in the afternoon) or not hungry (after lunch). One week later, they made a subsequent immediate choice, with an opportunity to change what they selected in advance. As predicted, Read and Van Leeuwen found that advance choices were influenced by current hunger and future hunger. Hungry participants chose more junk food than did those who were not hungry. In addition, participants chose significantly more junk food for immediate choice than for advance choice (see also Van Boven and Loewenstein 2003).

${ }^{6}$ Behavioral economics work on present-biased preferences distinguishes between naive and sophisticated agents, with the latter understanding the time inconsistency of their own preferences (e.g., O'Donoghue and Rabin 1999). 


\section{Policy Implications of Present-Biased Preferences}

Present-biased preferences can occur across a wide set of domains, both hot and cold. However, these problems are particularly problematic for various kinds of sin products, which explains poor consumer decisions about products with addictive characteristics and visceral properties, such as drugs, sex, and food.

For example, food consumption is a growing problem, and obesity is becoming a serious health concern. The implications of the intertemporal processes we described previously question the effectiveness of simply using cold informational approaches to improve food choice (cf. Verplanken and Wood 2006). For example, a standard approach to the problem of obesity is to explain to consumers the calorie contents of various foods they might eat in relation to recommended daily caloric contents (Chandon and Wansink 2005). Similarly, the Nutrition Education Labeling Act aimed to improve nutritional choices by better provision of nutrition information (Moorman 1996). Alternatively, companies might try to provide better information about the efficacy of various commercially available weight-loss products (Cleland et al. 1997). However, if unhealthful food choices arise from being in a hot state of hunger and in proximity to sinful foods, informational remedies may have limited success.

Another standard tool in the public policy arsenal is to increase the costs of socially undesirable behavior. According to the research we just reviewed, some such remedies used to discourage consumption of sin products do not work. The visceral-factors account shows that someone in a state of deprivation (i.e., a hot state) with a proximate visceral reward is highly insensitive to costs. This is the reason recovering alcoholics break down when they are in close proximity to alcohol. Similarly, increasing taxes on cigarettes will have little effect on consumption of cigarettes when someone is in a hot state of nicotine deprivation and in the proximity of triggering stimuli.

Therefore, we recommend consideration of another general policy remedy to dysfunctional impulsive behavior, namely, the institutionalization of precommitment devices to avoid yielding to temptation. Returning to our foodchoice example, one potential remedy for child obesity problems might be to make school lunch decisions at home for a week (or a month) at a time. This would reduce the possibility for impulsive, hot decisions while children are hungry and standing in line. Ironically, if people are given a choice of whether to order in advance or at the cafeteria, we expect that most people would choose the latter. They would fail to anticipate the hot/cold empathy gap and would perceive no benefit of removing the ability to choose at the last minute.

In another variant of the "removing-the-proximalstimulus" approach, schoolchildren could be encouraged to make better choices in the school lunch line by making choices before entering the line, with exposure to "surrogates" that make the tempting stimulus less tangible (i.e., pictures versus physical products; Shiv and Fedhorikhin 1999). Finally, in some domains, actual physical restraints could work (e.g., putting sugary cereals on high shelves in grocery stores so that young children cannot reach them).

\section{Present-Biased Preferences and Impulsiveness: Cognitive Determinants}

Thus far, we have associated impulsive behavior with "visceral" stimuli, but Zauberman and Lynch (2005) argue that similar impulsiveness and time inconsistency can arise when people approach any highly valued goal. That is, impulsiveness and time inconsistency need not be confined to hedonic or visceral sin products but can influence any purchase that invokes strong goal-approach motives. For example, Malkoc and Zauberman (2006) provide further evidence that the degree to which intertemporal preferences are present-biased depends on cognitive factors-in their case, the concreteness of the mental representation of events.

Cooling-off laws are an appropriate remedy for consumer "mistakes" due to extreme valuation of highly proximate products that lead to time-inconsistent preferences (Petty 1998; cf. McChesney 1984). A cooling-off period is simply some period of time in which a consumer has the option to "rescind, disaffirm, or revoke a contract, or more generally as a withdrawal right" (Rekaiti and Van den Bergh 2000, p. 371). For example, Connecticut requires a three-day cooling-off period that allows buyers of weight-loss program services to reconsider and have their money refunded (Cleland et al. 1997). Cooling-off laws could also mitigate some of the problems that arise from people's inability to anticipate their own preferences under different arousal states. Such laws need to include a period in which consumers are not allowed to "accept the offer made and conclude the contract" (Rekaiti and Van den Bergh 2000, p. 371). The main argument for this remedy is that it allows a correction for a market inefficiency caused by consumers' inability to exercise a choice that is consistent with their long-term interests. There is a debate about what is the "correct" preference. In this article, we argue only that most consumers should not regret their purchases after they make them.

We argued previously that liberal return policies can actually encourage consumers to buy under a false presupposition that they will later take the time to return a disappointing product. Cooling-off laws do not suffer from this problem because they do not endow the tentatively chosen product with default status or require effort to opt out, thus discouraging consumers from undoing a purchase they may regret a few days after buying.

\section{Conclusions}

This article provides a selective review of the most important issues in intertemporal choice research and its policy implications. We focused on two main themes: (1) devaluation of distant- versus near-future outcomes and (2) overvaluation of the present versus any other point in the future. We demonstrate that each of these phenomena has distinct implications that might require different interventions to help consumers make better decisions.

We reviewed two theories of the cognitive underpinnings of discounting: temporal construal theory (Trope and Liberman 2003) and resource slack theory (Zauberman and 
Lynch 2005). In both cases, the key implication for policy makers trying to induce some socially desirable pattern of behavior is to manipulate people's temporal perspective. If an action causes some mixture of costs and benefits, construal-level theory suggests that costs (and probabilities) will loom larger in the near term than in the more distant future. In the near term, the costs may outweigh the benefits, but when viewed from a greater temporal distance, the costs seem to fade away, and the benefits remain. To induce a pattern of long-term desirable behavior, people must be induced to precommit to a decision at some point in the more distant future. This is the concept underlying Thaler and Benartzi's (2004) Save More Tomorrow program, which induces people to save for retirement by changing the decision from saving in the present to saving in the future.

In other cases, the socially undesirable behavior comes from underweighting costs in the future. In this case, the policy prescription is the opposite; namely, induce people to make decisions about the future as if the consequences were effective immediately. This was the thrust of our recommendation for correcting implicit deception from rebates that require time investments in the future. People imagine having more time slack in the future than they actually experience, so they mispredict that they will redeem the rebates that induced them to purchase. We recommended regulations that require sellers to offer only rebates that must be redeemed immediately or class-action lawsuits to allow consumers redress if the recommended regulations prove inconsistent with prevailing FTC unfairness doctrine.

Our article also reviewed evidence showing that people overvalue the present compared with any other time period, resulting in inconsistent preferences over time. These timeinconsistent preferences can then lead to problems of selfcontrol. When viewing a situation from a distance, consumers may prefer to eat virtuous, healthful food rather than tempting, but unhealthful food. However, the same consumers may have problems upholding their decisions when the tempting food is proximate. If we acknowledge the affective and cognitive drivers that lead consumers to display present-biased preferences, we might be able to come up with more effective remedies.

Given these robust, myopic preferences, informational remedies are not likely to be effective, because these affectively driven decisions are controlled by brain processes that are unlikely to be accompanied by retrieval of information disseminated by regulators or companies. Instead, fundamentally different approaches are necessary, such as the institutionalization of self-control strategies that remove people from the tempting stimulus or that provide them recourse if they buy in the heat of the moment. Consumers are unlikely to adopt such self-control strategies independently if they mispredict the power of temptation as a result of the hot/cold empathy gap.

In summary, we argue that a better understanding of how consumers think about present and future consequences is critical to any public policy analysis of consumer decisions that include an intertemporal component. Future policy analysis of such decisions will benefit from attention to knowledge that is accumulated in this important stream of behavioral research.

\section{References}

Ainslie, George W. (1975), "Specious Reward: A Behavioral Theory of Impulsiveness and Impulse Control," Psychological Bulletin, 82 (April), 463-96.

and Nick Haslam (1992), "Hyperbolic Discounting," in Choice Over Time, George Loewenstein and Jon Elster, eds. New York: Russell Sage Foundation, 57-92.

and Richard Herrnstein (1981), "Preference Reversal and Delayed Reinforcement," Animal Learning and Behavior, 9 (4), 476-82.

Ariely, Dan and George Loewenstein (2006), "The Heat of the Moment: The Effect of Sexual Arousal on Sexual Decision Making," Journal of Behavioral Decision Making, 19 (2), 87-98.

and Klaus Wertenbroch (2002), "Procrastination, Deadlines, and Performance: Self-Control by Pre-Commitment," Psychological Science, 13 (3), 219-24.

Baker, Forest, Matthew W. Johnson, and Warren K. Bickel (2003), "Delay Discounting in Current and Never-Before Cigarette Smokers: Similarities and Differences Across Commodity, Sign, and Magnitude," Journal of Abnormal Psychology, 112 (3), 382-92.

Beales, J. Howard, III (2003), “The Federal Trade Commission's Use of Unfairness Authority: Its Rise, Fall, and Resurrection," Journal of Public Policy \& Marketing, 22 (Fall), 192-200.

Bertrand, Marianne, Sendhil Mullainathan, and Eldar Shafir (2006), "Behavioral Economics and Marketing in Aid of Decision Making Among the Poor," Journal of Public Policy \& Marketing, 25 (Spring), 8-23.

Botti, Simona and Sheena S. Iyengar (2006), "The Dark Side of Choice: When Choice Impairs Social Welfare," Journal of Public Policy \& Marketing, 25 (Spring), 24-38.

Brendl, C. Miguel, Arthur B. Markman, and Claude Messner (2003), "The Devaluation Effect: Activating a Need Devalues Unrelated Objects," Journal of Consumer Research, 29 (March), 463-73.

Briley, Donnel A. and Jennifer L. Aaker (2006), "Bridging the Culture Chasm: Ensuring That Consumers Are Healthy, Wealthy, and Wise," Journal of Public Policy \& Marketing, 25 (Spring), 53-66.

Chandon, Pierre and Brian Wansink (2005), "Is Obesity Caused by Calorie Underestimation? A Psychophysical Model of Meal Size Estimations," working paper, Department of Marketing, INSEAD.

Chapman, Gretchen B. (1996), "Temporal Discounting and Utility for Health and Money," Journal of Experimental Psychology: Learning, Memory, and Cognition, 22 (3), 771-91.

Cleland, Richard, Dean C. Graybill, Van Hubbard, Laura Kettle Khan, Judith Stern, Thomas A. Wadden, Roland Weinsier, and Susan Yanovski (1997), "Report of the Presiding Panel on Commercial Weight Loss Products and Programs: What Consumers Stand to Gain and Lose," report presented at the Public Conference on the Information Consumers Need to Evaluate Weight Loss Products and Programs, Federal Trade Commission Building, Washington, DC (October 16-17), (accessed January 24, 2006), [available at http://www.ftc.gov/os/1998/03/weightlo.rpt. $\mathrm{htm}]$.

— Walter C. Gross, Linda D. Koss, Matthew Dayard, and Karen Muoio (2002), "Weight Loss Advertising: A Review of 
Current Trends," report of the Staff of the Federal Trade Commission (September), (accessed January 24, 2006), [available at www.livingstrong.org/articles/weightloss.pdf].

Eyal, Tal, Nira Liberman, Yaacov Trope, and Eva Walther (2004), "The Pros and Cons of Temporally Near and Distant Action," Journal of Personality and Social Psychology, 86 (6), 781-95.

Fishbach, Ayelet and Yaacov Trope (2005), "The Substitutability of External Control and Self-Control," Journal of Experimental Social Psychology, 41 (3), 256-70.

Ford, Gary T. and Jack E. Calfee (1986), "Recent Developments in FTC Policy on Deception," Journal of Marketing, 50 (July), 82-103.

Frederick, Shane, George Loewenstein, and Ted O'Donoghue (2002), "Time Discounting and Time Preference: A Critical Review," Journal of Economic Literature, 40 (2), 351-401.

Freud, Sigmund ([1923] 1962), The Ego and the Id, trans. by Joan Riviere, rev. by James Strachey. New York: Norton Library.

(1933), The Dissection of the Psychical Personality: New Introductory Lectures on Psychoanalysis. New York: Norton.

FTC, Bureau of Consumer Protection (2001), "Dietary Supplements: An Advertising Guide for Industry," (accessed January 24, 2006), [available at www.ftc.gov/bcp/conline/pubs/buspubs/ dietsupp.pdf].

Gabaix, Xavier and David I. Laibson (2006), "Shrouded Attributes, Consumer Myopia, and Information Suppression in Competitive Markets," Quarterly Journal of Economics, 121 (3), forthcoming.

Kahneman, Daniel, Jack L. Knetsch, and Richard H. Thaler (1990), "Experimental Tests of the Endowment Effect and the Coase Theorem," Journal of Political Economy, 98 (6), 1325-49.

Kirby, Kris N. (1997), "Bidding on the Future: Evidence Against Normative Discounting of Delayed Rewards," Journal of Experimental Psychology: General, 126 (1), 54-70.

, Nancy M. Petry, and Warren K. Bickel (1999), "Heroin Addicts Have Higher Discount Rates for Delayed Rewards Than Non-Drug-Using Controls," Journal of Experimental Psychology: General, 128 (1), 78-87.

Laibson, David (1997), "Golden Eggs and Hyperbolic Discounting," The Quarterly Journal of Economics, 112 (2), 443-78.

Liberman, Nira, Michael Sagristano, and Yaacov Trope (2002), "The Effect of Temporal Distance on Level of Construal," Journal of Experimental Social Psychology, 38 (6), 523-34.

_ and Yacoov Trope (1998), "The Role of Feasibility and Desirability Considerations in Near and Distant Future Decisions: A Test of Temporal Construal Theory," Journal of Personality and Social Psychology, 75, 5-18.

$\longrightarrow$, and E. Stephan (in press), "Psychological Distance," in Social Psychology: Handbook of Basic Principles, Vol. 2, E. Tory Higgins and Arie W. Kruglanski, eds. New York: Guilford.

Loewenstein, George (1996), “Out of Control: Visceral Influences on Behavior," Organizational Behavior and Human Decision Processes, 65 (3), 272-92.

Madrian, Bridgette C. and Dennis F. Shea (2001), "The Power of Suggestion: Inertia in 401(k) Participation and Savings Behavior," Quarterly Journal of Economics, 116 (4), 1149-87.

Malkoc, Selin and Gal Zauberman (2006), "Deferring Versus Expediting Consumption: The Effect of Outcome Concreteness on Sensitivity to Time Horizon," Journal of Marketing Research, 43, forthcoming.

Mazar, Nina and Dan Ariely (2006), "Dishonesty in Everyday Life and Its Policy Implications," Journal of Public Policy \& Marketing, 25 (Spring), 117-26.

McChesney, Fred S. (1984), "Regulating Without Evidence: The FTC's 'Cooling-Off' Rule,' Journal of Contemporary Studies, 7 (Winter), 57-70.

McClure, Samual M., Davis I. Laibson, George Loewenstein, and Johathan D. Cohen (2004), "Separate Neural Systems Value Immediate and Delayed Monetary Rewards," Science, (October 15), 503-507.

Metcalfe, Janet and Walter Mischel (1999), "A Hot/Cool System Analysis of Delay of Gratification: Dynamics of Willpower," Psychological Review, 106 (1), 3-19.

Miller, James C., III (1983), "FTC Policy Statement on Deception," appended to Cliffdale Associates Inc., 103 F.T.C. 110, 174 (1984).

Moorman, Christine (1996), “A Quasi Experiment to Assess the Consumer and Informational Determinants of Nutrition Information Processing Activities: The Case of the Nutrition Labeling and Education Act," Journal of Public Policy \& Marketing, 15 (Spring), 28-44.

Mulholland, Joseph (2005), "Comments on 'When Do You Want It? Time, Decisions, and Public Policy' by John Lynch and Gal Zauberman," paper presented at the Conference on Helping Consumers Help Themselves, Duke University (May).

Nussbaum, Shiri, Yaacov Trope, and Nira Liberman (2003), "Creeping Dispositionism: The Temporal Dynamics of Behavioral Prediction," Journal of Personality and Social Psychology, 84 (3), 485-97.

O’Donoghue, Ted and Matthew Rabin (1999), "Doing It Now or Later," American Economic Review, 89 (March), 103-124.

Okrent, David (1999), “On Intergenerational Equity and Its Clash with Intragenerational Equity and on the Need for Policies to Guide the Regulation of Disposal of Wastes and Other Activities Posing Very Long-Term Risks," Risk Analysis, 19 (5), 877-901.

Petty, Ross D. (1998), "Interactive Marketing and the Law: The Future Rise of Unfairness," Journal of Interactive Marketing, 12 (3), 21-31.

Read, Daniel (2004), "Intertemporal Choice," in The Blackwell Handbook of Judgment and Decision Making, Derek J. Koehler and Nigel Harvey, eds. Oxford: Blackwell, 424-43.

- and Barbara van Leeuwen (1998), "Predicting Hunger: The Effects of Appetite and Delay on Choice," Organizational Behavior and Human Decision Processes, 76 (2), 189-205.

Rekaiti, Pamaria and Roger Van den Bergh (2000, "Cooling-Off Periods in the Consumer Laws of the EC Member States: A Comparative Law and Economic Approach," Journal of Consumer Policy, 23 (4), 371-407.

Sagristano, Michael D., Yaacov Trope, and Nira Liberman (2002), "Time-Dependent Gambling: Odds Now, Money Later," Journal of Experimental Psychology: General, 131 (3), 364-76.

Samuelson, Paul (1937), "A Note on Measurement of Utility," Review of Economic Studies, 4 (2), 155-61.

Samuelson, William and Richard Zeckhauser (1988), "Status Quo Bias in Decision Making," Journal of Risk and Uncertainty, 1 (1), 7-59. 
Shiv, Baba and Alexander Fedorikhin (1999), "Heart and Mind in Conflict: The Interplay of Affect and Cognition in Consumer Decision Making," Journal of Consumer Research, 26 (3), 278-92.

Silk, Tim (2004), "Getting Started Is Half the Battle: The Influence of Deadline Length and Procrastination on the Breakage of Mail-in Rebates," working paper, Moore School of Business, University of South Carolina.

(2005), "The Influence of Deadline Length on the Purchase and Redemption of Mail-in Rebates," working paper, Moore School of Business, University of South Carolina.

and Chris Janiszewski (2005), "Why Are Rebate Redemption Rates So Low? A Framework for Understanding Purchase and Non-Redemption of Mail-in Rebates," working paper, Moore School of Business, University of South Carolina.

Soman, Dilip (1998), "The Illusion of Delayed Incentives: Evaluating Future Effort-Money Transactions," Journal of Marketing Research, 35 (November), 427-38.

Strotz, Robert H. (1956), "Myopia and Inconsistency in Dynamic Utility Maximization," Review of Economic Studies, 23 (3), 165-80.

Thaler, Richard H. (1981), "Some Empirical Evidence on Dynamic Inconsistency," Economic Letters, 8 (3), 201-207.

and Shlomo Benartzi (2004), "Save More Tomorrow (TM): Using Behavioral Economics to Increase Employee Saving," Journal of Political Economy, 112 (1), 164-88.

and H.M. Shefrin (1981), "An Economic Theory of SelfControl," Journal of Political Economy, 89 (2), 392-410.

Trope, Yaacov and Nira Liberman (2000), “Temporal Construal and Time-Dependent Changes in Preference," Journal of Personality and Social Psychology, 79 (6), 876-89. and - (2003), "Temporal Construal," Psychological Review, 110 (3), 403-421.

Tversky, Amos and Eldar Shafir (1992), "Choice Under Conflict: The Dynamics of Deferred Decision," Psychological Science, 3 (6), 358-61.

Van Boven, Leaf and George Loewenstein (2003), "Projection of Transient Drive States," Personality and Social Psychology Bulletin, 29 (9), 1159-68.

Verplanken, Bas and Wendy Wood (2006), "Interventions to Break and Create Consumer Habits," Journal of Public Policy \& Marketing, 25 (Spring), 90-103.

Wade-Benzoni, Kimberly A. (1999), "Thinking About the Future: An Intergenerational Perspective on the Conflict and Compatibility Between Economic and Environmental Interests," American Behavioral Scientist, 42 (8), 1393-1405.

Wertenbroch, Klaus (1998), "Consumption Self-Control by Rationing Purchase Quantities of Virtue and Vice," Marketing Science, 17 (4), 317-37.

Wood, Stacy L. (2001), "Remote Purchase Environments: The Influence of Return Policy Leniency on Two-Stage Decision Processes," Journal of Marketing Research, 38 (May), 157-69.

Zauberman, Gal (2003), "The Intertemporal Dynamics of Consumer Lock-In," Journal of Consumer Research, 30 (3), 405-419.

and John G. Lynch Jr. (2005), "Resource Slack and Discounting of Future Time Versus Money," Journal of Experimental Psychology: General, 134 (1), 23-37.

Zhao, Min, Steve Hoeffler, and Gal Zauberman (2005), "Mental Simulation and Preference Consistency over Time: The Role of Process- Versus Outcome-Focused Thoughts," working paper, Kenan-Flagler School of Business, University of North Carolina, Chapel Hill. 
Copyright of Journal of Public Policy \& Marketing is the property of American Marketing Association and its content may not be copied or emailed to multiple sites or posted to a listserv without the copyright holder's express written permission. However, users may print, download, or email articles for individual use. 